\title{
Sustained Attention and Types of Dynamics of Cardiovascular Reactivity during a Short-Term, Human Whole-Body Exposure to Cold Air
}

\author{
Olga V. Krivonogova, PhD; Elena V. Krivonogova, PhD; Liliya V. Poskotinova, PhD, ScD* \\ N. Laverov Federal Center for Integrated Arctic Research of the Ural Branch of the Russian Academy of Sciences \\ Arkhangelsk, the Russian Federation
}

\begin{abstract}
Background: Despite global warming and the improvement of personal protective equipment against unfavorable climatic factors, cold remains an important environmental challenge for humans. The aim of the work was to reveal the peculiarities of the dynamics of cardiovascular parameters in humans with short-term, whole-body exposure to cold air, depending on the parameters of voluntary attention.

Methods and Results: The study involved 28 healthy male volunteers aged between 18 and 21 years, born and living in Arkhangelsk. Testing to assess sustained attention parameters using the Toulouse-Pierón Attention Test with the measurement of the index of accuracy (C, units) (the ability to voluntary concentration) and processing speed ( $\mathrm{V}$, units), had been previously performed. Subsequent stages of the study included recording the studied parameters before (Stage 1), during 10-minute exposure to the cold air (Stage 2), and 5 minutes after cold exposure (Stage 3). The registration of indicators in Stages 1 and 3 was carried out indoors at an air temperature of $+20^{\circ} \mathrm{C}$. The registration of indicators in Stage 2 was carried out in a cold chamber at $-20{ }^{\circ} \mathrm{C}$. Determining the body temperature in the ear canal $\left(\mathrm{T}_{\text {ear }},{ }^{\circ} \mathrm{C}\right)$ and on the skin of the dorsum of the right hand $\left(\mathrm{T}_{\text {skin }},{ }^{\circ} \mathrm{C}\right)$ was performed using a B.Well WF-1000 medical electronic infrared thermometer. Parameters of blood pressure (SBP and DBP) and heart rate variability (HRV) were evaluated.

As a result of cluster analysis, 2 groups were identified: Group $1(\mathrm{n}=14)$ and Group $2(\mathrm{n}=14)$. In Group 2, the index $\mathrm{V}$ was significantly lower than in Group $1(P=0.02)$. In Group $\mathrm{I}, \mathrm{T}_{\text {skin }}$ in Stage 1 was significantly higher than in Group $2(P=0.03)$. In Stage 2, Tskin decreased in both groups, but lower $\mathrm{T}_{\text {skin }}$ values $(P=0.001)$ were recorded in Group 2 than in Group I. In Stage 2, there was a statistically significant increase in SBP in Group $2(P=0.01)$. In Group 1, initial SDNN and all HRV spectral indices were significantly higher than in Group 2. In Stage 2, there was a significant increase in SDNN in both groups. However, in Group 2 , we found a statistically significant increase in VLF in Stage $2(P=0.01)$, while in Group I this indicator remained unchanged. In Stage 3, HRV parameters in Group 1 recovered to baseline values, while in Group 2, HRV parameters remained elevated relative to baseline values.

Conclusion: Individuals with high processing speed and preserved attention span have higher vagal activity and skin temperature. When such individuals are exposed to cold, they experience a moderate increase in BP and baroreflex response. In persons with a reduced speed of information processing but with sufficient accuracy of attention, there is a more pronounced mobilization of regulation resources on the part of the cardiovascular, neurovegetative systems to maintain the core temperature of the body.(International Journal of Biomedicine. 2020;10(4):407-411.)
\end{abstract}

Key Words: sustained attention • air cooling • cardiovascular reactivity

\section{Abbreviations}

BP, blood pressure; CIG, cardiointervalogram; DBP, diastolic BP; HR, heart rate; HRV, heart rate variability; SI, stress index; SBP, systolic BP; TP, total power.

\section{Introduction}

Despite global warming and the improvement of personal protective equipment against unfavorable climatic factors, cold remains an important environmental challenge for humans. An active study and development of the resource potential of the Arctic will be determined by a person's ability to adapt while maintaining his health and high mental 
performance. ${ }^{(1,2)}$ The impact of cold leads to a decrease in the functional reserves of the human body and to a decrease in mental performance..$^{(3)}$ During the migration of the population to the North and during the long-term adaptation of migrants to the conditions of high latitudes, the human cardiovascular system is one of the first to react. ${ }^{(4)} \mathrm{HRV}$ is formed under the control of the central nervous system and is associated with human mental health and such cognitive functions as memory and voluntary attention. Several studies have shown that adolescents living in the North have a lower ability to switch attention than adolescents living in more southern regions. In both adults and adolescents living in the North, sensorimotor reactions may be slower. ${ }^{(5)}$ The question remains, to what extent are the psychophysiological properties of a person related to the strategies of adaptive changes in regulatory systems when exposed to cold?

The aim of the work was to reveal the peculiarities of the dynamics of cardiovascular parameters in humans with short-term, whole-body exposure to cold air, depending on the parameters of voluntary attention.

\section{Materials and Methods}

The study involved 28 healthy male volunteers aged between 18 and 21 years, born and living in Arkhangelsk. The study was conducted in accordance with ethical principles of the WMA Declaration of Helsinki (1964, ed. 2013) and approved by the Ethics Committee of FECIAR UrB RAS (Protocol №2 of 03.28.2018). Written informed consent was obtained from all participants.

Volunteers had no signs of deficiency or excessive body weight (BMI of $18.5-25 \mathrm{~kg} / \mathrm{m}^{2}$ ), or fever (axillary temperature $\left.\leq 37^{\circ} \mathrm{C}\right)$.

The studies were carried out in the winter (JanuaryFebruary) in the morning in an office with a comfortable temperature regime. The exclusion criteria of the study were cardiovascular and neurological diseases, and increased sensitivity to cold (including Raynaud's syndrome).

Testing to assess sustained attention parameters using the Toulouse-Pierón Attention Test with the measurement of the index of accuracy $(\mathrm{C}$, units) (the ability to voluntary concentration) and processing speed (V, units), had been previously performed. Index $C$ was calculated as the ratio of correctly processed characters to the total number of characters processed; the index $\mathrm{V}$ was the number of characters processed per minute. ${ }^{(6)}$

Subsequent stages of the study included recording the studied parameters before (Stage 1), during 10-minute exposure to the cold air (Stage 2), and 5 minutes after cold exposure (Stage 3). Volunteers dressed in underwear, cotton trousers, winter boots and a cotton robe were examined in a sitting position at resting-state. The registration of indicators in Stages 1 and 3 was carried out indoors at an air temperature of $+20^{\circ} \mathrm{C}$. The registration of indicators in Stage 2 was carried out in a cold chamber at $-20^{\circ} \mathrm{C}$. Determining the body temperature in the ear canal $\left(\mathrm{T}_{\text {ear }}{ }^{\circ} \mathrm{C}\right)$ and on the skin of the dorsum of the right hand $\left(\mathrm{T}_{\text {skin }},{ }^{\circ} \mathrm{C}\right)$ was performed using a B.Well WF-1000 medical electronic infrared thermometer (Switzerland) before entering the chamber (Stage 1), on the 10th minute of being in the chamber (Stage 2) and the 5th minute after leaving the chamber (Stage 3).

BP (SBP and DBP) was determined using an A\&D medical device (Japan) before entering the chamber, immediately after leaving the chamber and in the 5th minute after leaving the chamber.

For the possibility of CIG recording under cold room conditions, we used a one-lead electrocardiogram channel of the Neuron-Spectrum-SM device, placed in a tank with thermal insulation. Subsequently, CIGs of the last 5 minutes in the cold chamber (Stage 2) and Stages 1 and 3 were processed using the Varicard instrument software (Ramena, Russia), and the HRV parameters were calculated. The following HRV parameters were evaluated: HR - heart rate, bpm; SDNN (msec) - the standard deviation of the normalto-normal RR intervals; SI (units) -Stress Index, calculated by the formula: $\mathrm{SI}=\mathrm{Amo} 50 / 2 \times \mathrm{VAR} \times \mathrm{Mo}$, where $\mathrm{Mo}$ ( $\mathrm{Msec}$ ) is the cardiointerval value dividing the CIG series in half; VAR - variation range between the minimum and maximum values in the CIG series, Amo50,\% -amplitude of mode number of R-R intervals; TP $\left(\mathrm{msec}^{2}\right)$ - Total Power of the HRV spectrum, HF $\left(\mathrm{msec}^{2}\right)$ - High Frequency Power of the HRV spectrum (0.15 to $0.40 \mathrm{~Hz})$; LF $\left(\mathrm{msec}^{2}\right)$ - LowFrequency Power of the HRV spectrum $(0.04-0.15 \mathrm{~Hz})$; VLF $\left(\mathrm{msec}^{2}\right)$ - Very Low Frequency power of the HRV spectrum (0.0033-0.04 Hz).

Statistical analysis was performed using the statistical software «Statistica» (v. 13.0, StatSoft, USA). The normality of distribution of continuous variables was tested by ShapiroWilk's W test. Median (Me) and interquartile range (IQR; 25th to 75 th percentiles) were calculated. The Mann-Whitney test was used to compare differences between two independent groups. The Friedman test was used to test for differences between 3 dependent samples, followed by post-hoc analysis with Wilcoxon signed rank test $(P<0.017)$. A clustering analysis using the k-means algorithm was performed.

\section{Results}

As a result of cluster analysis, 2 groups were identified: Group $1(\mathrm{n}=14)$ and Group $2(\mathrm{n}=14)$. In Group 2, the index V was significantly lower than in Group $1(P=0.02)$ (Table 1$)$.

Table 1.

Parameters of sustained attention in humans before whole-body exposure to cold air, $\mathrm{Me}\left(\mathrm{P}_{25} ; \mathrm{P}_{75}\right)$

\begin{tabular}{|c|c|c|c|}
\hline Parameter & Group 1 $(\mathrm{n}=14)$ & Group 2 $(\mathrm{n}=14)$ & $P$-value \\
\hline C, units & $0.97(0.94 ; 0.97)$ & $0.97(0.96 ; 0.98)$ & 0.190 \\
\hline V, units & $58.9(52.2 ; 65.6)$ & $50.7(41.9 ; 55.9)$ & 0.020 \\
\hline
\end{tabular}

In Group I, $T_{\text {skin }}$ in Stage 1 was significantly higher than in Group $2(P=0.03)$ (Table 2). In Stage 2, $\mathrm{T}_{\text {skin }}$ decreased in both groups, but lower $\mathrm{T}_{\text {skin }}$ values $(P=0.001)$ were recorded in 
young people in Group 2 than in Group I. $\mathrm{T}_{\text {ear }}$ also decreased in both groups and remained decreased in Stage 3 , as did $\mathrm{T}_{\text {skin }}$. In Stage 2, there was a tendency to increasing SBP in Group $1(P=0.02)$ and a statistically significant increase in SBP in Group $2(P=0.01)$. In Stage 2, DBP in both groups increased significantly $(P=0.001)$. In Stage 3 , DBP was similar to baseline values.

In Stage 1, HR in both groups was within the normal range, but in Group 2, its value was significantly higher than in Group 1. In Stage 3, HR was significantly lower, compared to the baseline value in both groups $(P<0.001)$.

In Group 1, initial SDNN and all HRV spectral indices were significantly higher than in Group 2. In Stage 2, there was a significant increase in SDNN and a decrease in SI in both groups. However, in Group 2, we found a statistically significant increase in VLF in Stage $2(P=0.01)$, while in Group I this indicator remained unchanged. In Stage 3, HRV parameters in Group 1 recovered to baseline values, while in Group 2, HRV parameters remained elevated relative to baseline values.

\section{Discussion}

Participants in Group 1 with a relatively high speed of information processing had a more pronounced baseline vagal activity and higher baseline $T_{\text {skin }}$ values than those in Group 2. SI values in Group 2 subjects reflected the trend of basic sympathicotonia.

A number of researchers believe that the activity of the divisions of the autonomic nervous system, reflected

Table 2.

Body temperature and cardiovascular parameters in humans during whole-body exposure to cold air $\left(M_{e}\left(P_{25} ; P_{75}\right)\right.$

\begin{tabular}{|c|c|c|c|c|c|c|c|c|}
\hline \multirow{2}{*}{ Parameters } & Stage I & Stage 2 & Stage 3 & \multirow{2}{*}{$\begin{array}{c}P \\
\text { Friedman }\end{array}$} & Stage I & Stage 2 & Stage 3 & \multirow{2}{*}{$\begin{array}{c}P \\
\text { Friedman }\end{array}$} \\
\hline & 1 & 2 & 3 & & 1 & 2 & 3 & \\
\hline $\mathrm{T}_{\text {skin }},{ }^{\circ} \mathrm{C}$ & $34.5(29.0 ; 35.7)$ & $\begin{array}{c}20.1(19.1 ; 21.1) \\
\#^{(1-2)}\end{array}$ & $\begin{array}{c}24.1(23.9 ; 25.7) \\
\# \#^{(1-3)}\end{array}$ & $<0.001$ & $\begin{array}{c}27.7(26.2 ; 33.0) \\
*\end{array}$ & $\begin{array}{c}16.9(19.1 ; 18.9) \\
* * \# \#^{(1-2)}\end{array}$ & $\begin{array}{c}22.1(21.1 ; 24.0) \\
\# \#^{(1-3)}\end{array}$ & $<0.001$ \\
\hline $\mathrm{T}_{\text {ear }},{ }^{0} \mathrm{C}$ & $36.3(36.1 ; 36.3)$ & $\begin{array}{c}34.1(33.6 ; 34.8) \\
\# \#^{(1-2)}\end{array}$ & $\begin{array}{c}35.2(34.7 ; 35.6) \\
\# \#^{(1-3)}\end{array}$ & 0.001 & $36.3(36.1 ; 36.4)$ & $\begin{array}{c}34.5(33.6 ; 34.7) \\
\#^{(1-2)}\end{array}$ & $\begin{array}{c}35.0(34.8 ; 35.7) \\
\# \#^{(1-3)}\end{array}$ & 0.001 \\
\hline $\begin{array}{l}\text { SBP, } \\
\mathrm{mmHg}\end{array}$ & $127(121 ; 130)$ & $132(123 ; 136)$ & $\begin{array}{c}123.5(117 ; 130) \\
\# \#^{(2-3)}\end{array}$ & 0.003 & $121.5(112 ; 133)$ & $\begin{array}{c}134(120 ; 140) \\
\#^{(1-2)}\end{array}$ & $\begin{array}{c}127(112 ; 132) \\
\# \#^{(2-3)}\end{array}$ & 0.006 \\
\hline HR, bpm & $70.9(62.3 ; 76.2)$ & $70.2(64.3 ; 75.4)$ & $\begin{array}{c}65.1(61.1 ; 68.6) \\
\# \#(1-3)\end{array}$ & $<0.001$ & $\begin{array}{c}78.9(71.4 ; 88.7) \\
*\end{array}$ & $76.5(71.5 ; 80.1)$ & $\begin{array}{c}70.1(64.6 ; 76.8) \\
\# \#^{(1-3)}\end{array}$ & 0.003 \\
\hline $\begin{array}{l}\text { SDNN, } \\
\text { msec }\end{array}$ & $72.5(44.7 ; 84.9)$ & $\begin{array}{c}92.1(82.8 ; 131.4) \\
\# \#(1-2)\end{array}$ & $76.5(60.0 ; 106.8)$ & 0.001 & $\begin{array}{c}41.9(36.3 ; 49.3) \\
* *\end{array}$ & $\begin{array}{c}78.5(55.9 ; 82.2) \\
\# \#^{(1-2)}\end{array}$ & $\begin{array}{c}66.3(51.5 ; 106.3) \\
\# \#^{(1-3)}\end{array}$ & $<0.001$ \\
\hline SI, unit & $49.2(30.5 ; 100.5)$ & $\begin{array}{c}30.9(17.6 ; 53.6) \\
\# \#(1-2)\end{array}$ & $38.9(18.2 ; 59.6)$ & $<0.001$ & $\begin{array}{c}132.2(94.6 ; 176.8) \\
* *\end{array}$ & $\begin{array}{c}46.6(36.9 ; 85.4) \\
\#^{(1-2)}\end{array}$ & $\begin{array}{c}54.7(25.3 ; 102.6) \\
\# \#(1-3)\end{array}$ & $<0.001$ \\
\hline $\begin{array}{l}\mathrm{TP} \times 1000 \\
\mathrm{msec}^{2}\end{array}$ & $3.77(2.81 ; 6.15)$ & $\begin{array}{c}7.16(4.36 ; 13.95) \\
\# \#(1-2)\end{array}$ & $5.68(3.95 ; 10.13)$ & 0.005 & $\begin{array}{c}1.78(1.24 ; 2.31) \\
* *\end{array}$ & $\begin{array}{c}4.69(2.94 ; 6.21) \\
\#^{(1-2)}\end{array}$ & $\begin{array}{c}3.76(2.63 ; 7.13) \\
\# \#(1-3)\end{array}$ & $<0.001$ \\
\hline $\begin{array}{l}\text { VLF } \\
\times 1000, \\
\mathrm{msec}^{2}\end{array}$ & $0.95(0.56 ; 1.62)$ & $0.95(0.66 ; 2.51)$ & $1.16(0.78 ; 1.53)$ & 0.807 & $\begin{array}{c}0.30(0.20 ; 0.40) \\
* *\end{array}$ & $\begin{array}{c}0.57(0.32 ; 0.74) \\
\# \#^{(1-2)}\end{array}$ & $\begin{array}{c}1.07(0.51 ; 1.53) \\
\# \#(1-3)\end{array}$ & 0.031 \\
\hline
\end{tabular}

$* P<0.05$, ** $P<0.01$ - between groups in same stage (Mann-Whitney test); \#\# $P<0.01$ - between stages in each group (Wilcoxon test). 
in the parameters of the variability of cardiac activity, is associated with the regulation of attention processes. ${ }^{(7)}$ The frontal thalamic system, which includes the prefrontal cortex and mediodorsal nucleus of the thalamus, ${ }^{(8)}$ is the main neural regulatory system for voluntary attention.There is also a functional relationship between HRV parameters and the activity of the prefrontal cortex, ${ }^{(9)}$ as well as between vagus tone and attention control processes. ${ }^{(7)}$ Higher HRV is associated with better cognitive functions such as memory and attention. ${ }^{(10)}$ G. Park showed that people with lower HRV needed more time to solve problems with distractions; at the same time, participants with a higher HRV showed a more effective control of selective attention. ${ }^{(10,11)}$ A. Hansen et al. ${ }^{(12)}$ showed that male sailors with high HRV had a faster response to a stimulus, more correct answers, and fewer errors than the group with low HRV. It is believed that sympathetic influences on HR function are relatively slow (on the order of seconds) compared to the effects of the vagus nerve (on the order of milliseconds). Thus, in a person with a relative deficit in vagal modulation on the HR, the ability to track environmental challenges and the reactivity of the nervous system is reduced. ${ }^{(7,9)}$

When exposed to cold, afferent sensory information from peripheral skin thermoreceptors is integrated in the hypothalamus, subsequently contributing to peripheral vasoconstriction, especially in the skin area through the activation of adrenergic nerve fibers. Despite an identical decline rate $T_{\text {ear }}$ in both groups, which is closest to the core of the body, it is obvious that individuals with a lower concentration of attention (Group 2) experienced a more pronounced decrease in $\mathrm{T}_{\text {skin }}$, which reflects a more pronounced effect of peripheral vasoconstriction to limit heat transfer and maintain core temperature.

The pronounced adrenergic activation in response to cold also caused a significant reaction of the stroke volume in the great vessels and a pronounced increase in not only DBP but also SBP in persons of Group 2. As a response to a sharp increase in BP, we observed a decrease in baroreflex modulation of HR, and an increase in total HRV and LF band of the HRV spectrum in both groups. However, persons with a lower speed of voluntary attention had a more pronounced response of VLF band of the HRV spectrum to the effect of cold, which indicates the activation of the central ergotropic mechanisms of regulation; ${ }^{(13)}$ that is, in persons with a lower speed of information processing and with a tendency to basic sympathicotonia, the response to cooling will be more pronounced with the involvement of the central mechanisms of the autonomic nervous system regulation of HR. It is assumed that this type of reaction is aimed at long-term resistance of the body to the damaging effects of cold.

In conclusion, individuals with high processing speed and preserved attention span have higher vagal activity and skin temperature. When such individuals are exposed to cold, they experience a moderate increase in BP and baroreflex response. Such an adaptive strategy can be in demand either with short-term exposure to cold or in individuals with high adaptive capabilities of thermogenesis with a minimal shift in hemodynamic parameters.
In persons with a reduced speed of information processing but with sufficient accuracy of attention, there is a more pronounced mobilization of regulation resources on the part of the cardiovascular, neurovegetative systems to maintain the core temperature of the body. Such an adaptive strategy can be biologically expedient for the human body under conditions of long-term exposure to cold, for which large energy resources of the body can be involved. However, with more pronounced sympathicotonia and persistence of high BP after exposure to cold, the risk for cold hypertension and tissue damage increases.

\section{Competing Interests} interests.

The authors declare that they have no competing

\section{Sources of Funding}

The reported study was funded by the FECIAR UrB RAS according to the research project No AAAA-A19-119120990083-9.

\section{References}

1. Gudkov AB, Lukmanova NB, Ramenskaya EB. [The man in the circumpolar region of the European North: ecological and physiological aspects]. Arkhangelsk: NARFU CPI; 2013. [In Russian].

2. Bekmansurov KhA, Bildanova VR. [Mental performance as a test of integrative health]. Psychological and pedagogical support of the educational process. Regional collection of scientific papers. Elabuga; EGPU;2006:55-59. [Article in Russian].

3. Gudkov AB, Uvarova IP, Popova ON, Lukmanova NB, Pashchenko VP. [Physiological Reactions of Cardiocirculatory System to Local Cooling of Extremities in Young Male and Female, Natives of European North]. Ekologiya Cheloveka. 2017;2:22-26. doi: 10.33396/1728-0869-2017-2-22-26. [Article in Russian].

4. Dorshakova NV, Karapetyan TA. [Features of pathology of northern residents]. Ekologiya Cheloveka. 2004;6:48-52. [Article in Russian].

5. Solonin YG. [Studies on latitude physiology (Review)]. Journal of Medical and Biological Research. 2019;7(2):228 239.doi:10.17238/issn2542-1298.2019.7.2.228. [Article in Russian].

6. Yasukawa LA. [Optimization of the learning and development of children with MMD]. Diagnostics and compensation of minimal brain dysfunctions. Methodological guidance. St. Petersburg: GP «Imaton»; 1997. [In Russian]. 7. Thayer JF, Lane RD. A model of neurovisceral integration in emotion regulation and dysregulation. J Affect Disord. 2000 Dec;61(3):201-16. doi: 10.1016/s0165-0327(00)00338-4.

*Corresponding author: Liliya V. Poskotinova, PhD, ScD. Department of Biorhythmology of N. Laverov Federal Center for Integrated Arctic Research of the UrB of the RAS, Arkhangelsk, Russia.E-mail: liliya200572@mail.ru 
8. Machinskaia RI. Neŭrofiziologicheskie mekhanizmy proizvol'nogo vnimaniia (analiticheskiĭ obzor) [Neurophysiological mechanisms of voluntary attention: a review]. Zh Vyssh Nerv Deiat Im I P Pavlova. 2003 Mar-Apr;53(2):133-50. [Article in Russian].

9. Forte G, Favieri F, Casagrande M. Heart Rate Variability and Cognitive Function: A Systematic Review. Front Neurosci. 2019 Jul 9;13:710. doi: 10.3389/fnins.2019.00710.

10. Siennicka A, Quintana DS, Fedurek P, Wijata A, Paleczny B, Ponikowska B, Danel DP. Resting heart rate variability, attention and attention maintenance in young adults. Int J Psychophysiol. 2019 Sep;143:126-131. doi: 10.1016/j. ijpsycho.2019.06.017.

11. Park G, Vasey MW, Van Bavel JJ, Thayer JF. Cardiac vagal tone is correlated with selective attention to neutral distractors under load. Psychophysiology. 2013 Apr;50(4):398-406. doi: 10.1111/psyp.12029.

12. Hansen AL, Johnsen BH, Sollers JJ 3rd, Stenvik K, Thayer JF. Heart rate variability and its relation to prefrontal cognitive function: the effects of training and detraining. Eur J Appl Physiol. 2004 Dec;93(3):263-72. doi: 10.1007/s00421004-1208-0.

13. Fleishman AN, Korablina TV, Petrovsky SA, Martynov ID. [Complex structure and nonlinear behavior of very low frequency of heart rate variability: model of analysis, and practical applications]. Izvestia VUZ: Applied nonlinear dynamics. 2014;22(1):55-70 doi: 10.18500/0869-6632-201422-1-55-70. [Article in Russian]. 